\title{
Do remittances promote human development? Empirical evidence from developing countries
}

\begin{abstract}
Purpose: The purpose of this paper is to analyse the impact of remittances on human development in developing countries using panel data from 1980 to 2014 and to address the critical question of whether the increasing trend of remittances has any impact on human development in a broad range of developing countries. Design/methodology/ approach: Usual panel estimates, such as pooled OLS, fixed or random effects model, possess specification issues such as endogeneity, heterogeneity and measurement errors. In this paper, we, therefore, apply dynamic panel estimates - System generalised method of moment (Sys-GMM) developed by Arellano and Bond (1991) and Arellano and Bover (1995). This estimator is able to control for the endogeneity of all the explanatory variables, account for unobserved country-specific effects that cannot be done using country dummies due to the dynamic structure of the model (Azman-Saini et $a l ., 2010)$. Findings: The effect of remittances is statistically significant with positive coefficients in developing countries. The significant coefficient of remittances means that, holding other variables constant, a rise in remittance inflows is associated with improvements in human development. A 10 per cent increase in remittances will lead to an increase of approximately 0.016 per cent in human development. These findings are consistent with Üstubuci and Irdam (2012) and Adenutsi (2010), who found evidence that remittances are positively correlated with human development. Practical implications: The paper considers implications for policymakers to justify the need for more effective approaches. Policymakers need to consider indicators of human development and to devise public policies that promote income, health and education, to enhance human development. Originality/value: The question of whether remittances affect human development has rarely been subject to systematic empirical study. Extant research does not resolve the endogeneity problem, whereas the present study provides empirical evidence by utilising dynamic panel estimators such as Sys-GMM to tackle the specification issues of endogeneity, measurement errors and heterogeneity. The present study provides a benchmark for future research on the effect of remittances on human development.
\end{abstract}

Keyword: Developing countries; Human development; Remittances 
